\title{
Science high on French political agenda
}

Science has made an unexpectedly strong showing in the government of François Fillon, prime minister of France's newly elected president, Nicolas Sarkozy. The environment and energy, in both the French media and government, have become à la mode.

Ecology and sustainable development, long relegated to puny ministries, have been propelled to a top-rank superministry. And at its helm is a political heavyweight - Alain Juppé, a former prime minister and foreign minister. The ministry will have responsibility for the huge sectors of transport, urban and rural planning, energy policy, and other ecological areas such as biodiversity, water and pollution.

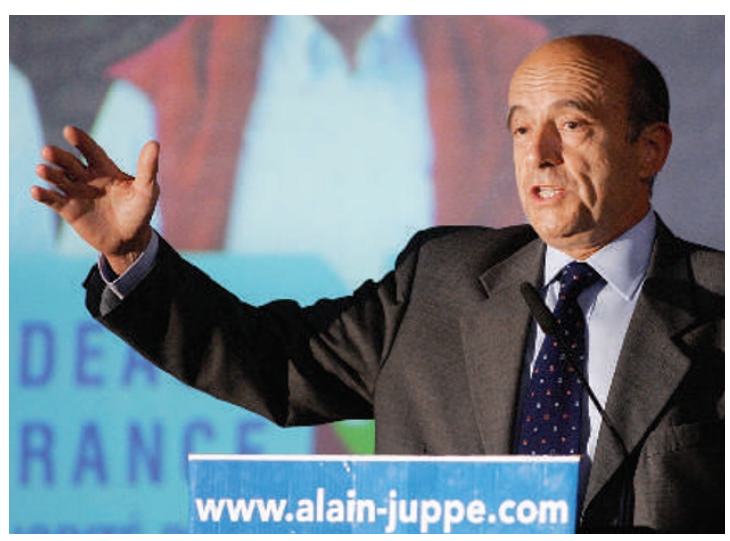

Grand gestures: Alain Juppé has taken the reins at France's new superministry for ecology and sustainable development.
Science and higher education have been granted a full-blown ministry, too, headed by Valérie Pécresse. The move was by no means guaranteed, given that Sarkozy has halved the number of ministers in his government to 15 , and that the previous government allotted these sectors only junior status. Bernard Kouchner, co-founder of the medical humanitarian aid group Médecins Sans Frontières and a member of the opposition socialist party, has been appointed foreign minister. And Fillon, a moderate conservative, is himself no stranger to these areas: he served as research and highereducation minister in 1993-95 and 2004-05.

Much of the credit for getting the environment so high on the political agenda must go to Nicolas Hulot, a highly popular TV environmentalist, journalist and writer. During the presidential election campaign, the Nicolas Hulot Foundation asked candidates to sign up to a ten-point ecological pact pledging a radical revision of policies, including energy, transport and agriculture, and to address climate change, species extinction, pollution and other environmental issues. In the face of Hulot's massive popular support (polls showed that had he run, he could have won as much as $10 \%$ of the vote), candidates, including Sarkozy, queued up to sign.

It is too soon to say how the creation of France's superministry will translate into actions. But the scale of the government's environmental commitments on paper is "historic", says Yvon Le Maho, a biodiversity researcher at the Hubert Curien Multidisciplinary Institute in Strasbourg. Le Maho, along with several green non-governmental organizations, attended a planning meeting with Sarkozy and Juppé on 21 May to help hammer out a comprehensive five-year plan for the environment. "To be at such a meeting just days after Sarkozy took office was completely surreal," he says.

The government's surprising ecological bent could also make for an interesting G8 meeting, which is scheduled for 6-8 June in the more traditionally green Germany.

Declan Butler

\section{Complex set of RNAs found in simple green algae}

A class of RNA molecule, called a microRNA, has been found in a unicellular green alga. The discovery, made independently by two labs, dismantles the popular theory that the regulatory role of microRNAs in gene expression is tied to the evolution of multicellularity.

The researchers confirmed the existence of dozens of microRNAs in the genome of the green alga Chlamydomonas reinhardtii, and think that hundreds are likely. The finding is as startling as the discovery ten years ago that the nematode Caenorhabditis elegans has 19,000 genes, just 1,000 short of the human count, says Gregory Hannon from Cold Spring Harbor Laboratory in New York and a co-author of one of the studies (T. Zhao et al. Genes Dev. 21, 1190-1203; 2007). “People were shocked that the complexity of the genomes in these simpler creatures was similar to our own," he says. Now it seems that the RNA in simple unicellular organisms could be as complex as that in higher creatures.

The second study, which independently came to the same conclusion, appears online in Nature this week (A. Molnár et al. doi:10.1038/nature05903; 2007).

Ever since the discovery of RNA interference - the selective blocking of gene expression by small RNAs - biologists have identified a growing family of these tiny molecules in eukaryotic organisms. But hunts in yeast and in the protist Tetrahymena have yielded fewer types of RNA molecule than found in plants and animals. MicroRNAs were never found.

This, combined with the fact that RNA sequences differ between plants and animals, helped give rise to the idea that microRNAs

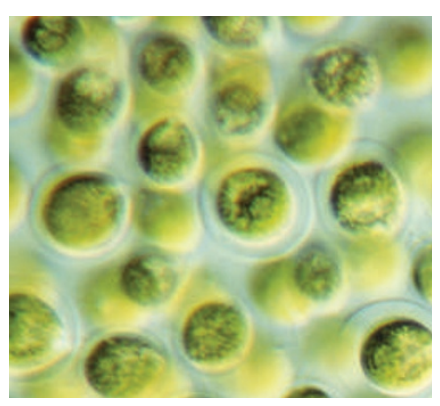

MicroRNAs found in green algae hint at the organism's complexity.

evolved independently in plant and animal lineages as parts of complex regulatory mechanisms associated with multicellularity. Now it seems that these molecules may predate that evolutionary development.

"It shows how basing conclusions on studies of just one or two model organisms can really lead you astray in terms of how you think about evolutionary processes," says Jim Umen from the Salk Institute in La Jolla, California.

A combination of factors led to the recent findings: high-throughput sequencing can now sieve through thousands of RNA molecules in search of microRNA. And having a nearly completed map of the genome for the alga means that its sequences can be interpreted relatively easily.

Nobody knows why such a simple organism needs microRNAs, nor how or when they first appeared. But researchers say they may help C. reinhardtii adapt to extremely diverse environments.

Whatever their role, their presence indicates that microRNAs could be much more ancient than previously thought; they might have persisted for more than a billion years.

Lucy Odling-Smee 